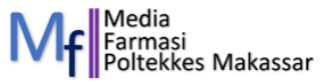

\title{
UJI AKTIVITAS SENYAWA BIOAKTIF ANTIMIKROBA DARI EKSTRAK DAUN SEMBUKAN (Paederia foetida L.) PADA BAKTERI Staphylococcus aureus DENGAN METODE BIOAUTOGRAFI
}

\author{
Samsidar Usman*), Ismail Ibrahim**) \\ ${ }^{*}$ Fakultas Farmasi Universitas Indonesia Timur Makassar \\ **) Jurusan Farmasi Poltekkes Kemenkes RI Makassar \\ *) E-mail korespondensi : samsidar27782@gmail.com
}

DOI: https://doi.org/10.32382/mf.v13i2.881

\begin{abstract}
ABSTRAK
Tujuan dari penelitian ini adalah untuk mengetahui senyawa bioaktif antimikroba ekstrak daun Sembukan (Paederia foetida L.) yang memiliki efektifitas terhadap Staphylococcus aureus dengan metode Bioautografi. Bahan uji dari penelitian ini adalah daun sembukan (Paederia foetida L.) dan sampel yang digunakan adalah Staphylococcus aureus. Berdasarkan hasil penelitian yang telah dilakukan maka dapat disimpulkan bahwa Uji Senyawa Bioaktif Ekstrak Daun Sembukan (Paederia foetida L.) dapat memberikan efektifitas terhadap pertumbuhan Staphylococcus aureus pada ekstrak eter daun sembukan dengan nilai $R f 0,85$ dengan zona hambat $4,75 \mathrm{~mm}$, nilai $R f 0,82$ zona hambat $6,5 \mathrm{~mm}$, nilai $R f 0,84$ zona hambat $6,25 \mathrm{~mm}$ dan ekstrak n-Butanol nilai $R f 0,35$ dengan zona hambat $5,25 \mathrm{~mm}$, nilai $R f 0,47$ zona hambat $6,75 \mathrm{~mm}$, nilai $R f 0,37$ zona hambat 9,5 $\mathrm{mm}$.
\end{abstract}

\section{Kata kunci : Daun Sembukan (Paederia foetida L.), Staphylococcus aureus, Bioautografi}

\section{PENDAHULUAN}

Manusia hidup di alam selalu kontak dengan mikroorganisme, bakteri, virus dan berbagai bentuk kehidupan parasit lainnya. Penyakit infeksi timbul apabila mikroorganisme yang masuk ke dalam tubuh menyebabkan berbagai gangguan fisiologis normal tubuh. Oleh karena itu dilakukan usaha untuk mengatasi penyakit infeksi dengan memanfaatkan obat tradisional. Obat tradisional merupakan obat yang banyak digunakan oleh masyarakat Indonesia. Obat tradisional juga merupakan salah satu pengganti atau pengobatan alternatif dalam penyembuhan suatu penyakit pada masa sekarang ini, dengan cara pemanfaatan bahan-bahan alam khususnya tanaman yang mengandung bahan obat untuk pengobatan suatu penyakit. Namun demikian baru sedikit yang telah dibuktikan kandungan kimia dan aktivitas biologisnya.

Berbagai jenis bakteri saat ini semakin kuat menghancurkan kerja antibiotik. Mekanisme pertahanan yang seharusnya dipakai antibiotik untuk melawan infeksi mampu dihancurkan oleh bakteri, tak terkecuali dengan Staphylococcus aureus, bakteri tersebut merupakan jenis bakteri patogen dan dapat menyebabkan pneumonia, meningitis, epyema, endocarditis, pioderma, impetigo dan sepsis dengan supurasi pada berbagai organ (Ervizal, 2011).

Melihat perkembangan resistensi Staphylococcus aureus yang meningkat sangat perlu untuk mengembangkan obatobat antibakteri alternatif seperti pemanfaatan obat tradisional. Penggunaan bahan alam sebagai obat tradisional di Indonesia telah dilakukan oleh nenek moyang kita sejak ratusan tahun yang lalu. Tumbuhan yang digunakan untuk obat tradisonal dapat dijadikan alternatif pencarian zat antimikroba baru (Ervizal, 2011). Banyak sekali tumbuhan yang dapat di manfaatkan sebagai obat tradisional salah satunya adalah daun sembukan.

Mikroorganisme adalah mahluk hidup yang berukuran sangat kecil. Aktivitas kehidupannya bergantung pada keadaan sekitar dan dapat mempengaruhi kehidupan manusia sebagai penyebab terjadinya berbagai macam penyakit yang merugikan. Penyakit yang dapat disebabkan antara lain gatal, rasa sakit, infeksi dan dapat mengganggu penampilan dan masih banyak lagi penyakit lainnya, sehingga masih menjadi masalah yang serius untuk ditangani. 
Langkah pengobatan untuk penyakit infeksi antimikroba ini adalah dengan pemberian agen antimikroba yang dapat menghambat pertumbuhan atau membunuh mikroba yang menginfeksi. Agen antimikroba sekarang ini telah banyak ditemukan, tetapi beberapa diantaranya tidak efektif digunakan karena banyaknya mikroba yang resisten dan efek sampingnya sangat merugikan penderita (Wasito,dkk 2013).

Tumbuhan sembukan, kasembukan atau yang sering disebut dengan daun kentut merupakan salah satu jenis tumbuhan obat Indonesia. Tumbuhan ini berasal dari Asia Timur, tetapi sekarang tersebar di daerah tropis seluruh dunia. Secara ilmiah tumbuhan ini disebut Paederia foetida L. Keterangan foetida menunjukkan bahwa tumbuhan berbau busuk (Nurcahyanti dan Wandra, 2012).

Tumbuhan sembukan telah banyak diteliti di daerah luar Sulawesi. Beberapa literatur menyebutkan bahwa tumbuhan sembukan banyak diekstrak menggunakan pelarut yang bersifat polar. Seperti penelitian Abriyanto dkk, (2012) melakukan uji aktivitas anti fungi dari ekstrak etanol sembukan. Selain itu, Mirnawati dkk (2011) melakukan uji aktivitas antibakteri terhadap ekstrak n-Heksana batang Sembukan (Paederia foetida L.) yang positif menghambat $B$. subtilis dan $P$. aureginose.

Kandungan kimia dari tumbuhan sembukan adalah asperulosida, skandosida, paederosida, deasetilasperulosida, asam paederosida, arbutin, asam oleonik, dan gama sitosterol. Daun sembukan memiliki bau yang tidak enak dan tidak bersifat permanen, karena apabila daun direbus atau dikukus aromanya akan berkurang.

Daun sembukan ini telah dimanfaatkan sebagai tanaman obat yaitu untuk mengobati perut kembung. Selain itu juga dapat mengobati mata bengkak, penyakit maag, disentri, dan herpes (Shetty, dkk, 2012). Selain itu dapat mengobati reumatik, hepatitis, batuk, beri-beri, antibakteri, mengurangi rasa nyeri atau analgesik, dan penenang atau sedatif (Khare, 2010).

Selain itu, ekstrak etanol daun sembukan (Paederia foetida L.) mempunyai aktivitas antibakteri terhadap Enterococcus faecalis, Shigella flexneri, dan Echerichia coli (Yenny Herwanna, 2013). Staphylococcus aureus adalah bakteri Gram positif yang dapat ditemukan di kulit dan di hidung manusia dan terkadang dapat menyebabkan infeksi dan sakit parah.

Penggunaan daun sembukan (Paederia foetida L.) dapat dilakukan untuk menguji aktivitas senyawa bioaktif antimikroba yang dimiliki daun sembukan (Paederia foetida L.) melalui metode bioautografi. Metode bioautografi yang merupakan metode spesifik yang digunakan untuk mendeteksi bercak pada kromatogram hasil kromatografi lapis tipis yang mempunyai aktivitas sebagai antibakteri, antifungi dan antiviral.

Berdasarkan paparan diatas maka penulis tertarik untuk melakukan penelitian dengan judul “ Uji senyawa bioaktif antimikroba dari ekstrak Daun Sembukan (Paederia foetida L.) terhadap Staphylococcus aureus melalui metode Bioautografi"

Tujuan dari penelitian ini adalah Untuk mengetahui senyawa bioaktif ekstrak Daun Sembukan (Paederia foetida L.) yang dapat menghambat pertumbuhan Staphylococcus aureus dengan menggunakan metode Bioautografi.

\section{METODE DAN BAHAN \\ Jenis Penelitian}

Jenis penelitian ini adalah eksperimental yang merupakan penelitian laboratorium dengan menggunakan metode Bioautografi dengan pengujian senyawa bioaktif antimikroba dari ekstrak Daun Sembukan (Paederia foetida L.) asal Kecamatan Herlang,Kabupaten Bulukumba Provinsi Sulawesi Selatan.

\section{Waktu dan Tempat Penelitian}

Penelitian ini telah dilaksanakan di Laboratorium Fitokimia Farmasi dan Laboratorium Mikrobiologi Farmasi Fakultas Farmasi Universitas Indonesia Timur Makassar pada bulan Agustus 2017.

\section{Alat dan Bahan}

1. Alat yang Digunakan Bahan yang digunakan dalam penelitian ini adalah, Ekstrak Daun Sembukan (Paederia foetida L.), aquadest, etanol $96 \%$, etil asetat, $\mathrm{CHCl}_{3}$, metanol pa, hexan, kapas, kertas saring, label, 
medium Nutrien Agar (NA), Plat KLT Silika Gel F254

2. Bahan yang Digunakan

Bahan yang digunakan dalam penelitian ini adalah, Ekstrak Daun Sembukan (Paederia foetida L.), aquadest, etanol $96 \%$, etil asetat, $\mathrm{CHCl}_{3}$, metanol pa, hexan, kapas, kertas saring, label, medium Nutrien Agar (NA), Plat KLT Silika Gel F254.

\section{Pengambilan dan Pengolahan Bahan Uji}

1. Pengambilan Bahan Uji

Pengambilan rimpang daun Sembukan (Paederia foetida L.) dilakukan pada pagi hari. Metode pengambilan sampel dilakukan secara sampling purposif yang dikenal juga sebagai sampling pertimbangan dimana sampel yang akan digunakan adalah daun Sembukan asal Kecamatan Herlang Kabupaten Bulukumba Provinsi Sulawesi Selatan.

2. Pengolahan Bahan Uji

Pengolahan daun Sembukan dibersihkan dari kotoran yang melekat, disortasi basah di bawah air mengalir hingga bersih, lalu dipotong kecil-kecil, dikeringkan dengan cara dianginanginkan pada suhu kamar.

Bahan yang telah dikeringkan, terlebih dahulu ditimbang sebanyak 500 gram, lalu dibungkus dengan aluminium foil (alfol) dan siap untuk dilakukan ekstraksi.

\section{Prosedur kerja.}

1. Ekstraksi sampel dengan metode maserasi

Daun Sembukan (Paederia foetida L.) yang telah dikeringkan ditimbang sebanyak 350 gram dimaserasi dengan Etanol $96 \%$ hingga diperoleh ekstrak etanol 96\%. Kemudian dilanjutkan Ekstraksi Dengan Pelarut Dietil Eter dimana Ekstrak kental yang diperoleh, terlebih dahulu ditambahkan dengan air sebanyak $50 \mathrm{ml}$ hingga terdispersi, kemudian ditambahkan dengan pelarut dietil eter sebanyak $50 \mathrm{ml}$ lalu dimasukkan ke dalam corong pisah. terbentuk dua lapisan untuk lapisan air disimpan dalam wadah, lapisan eter diangin-anginkan hingga diperoleh ekstrak eter kering. Kemudian dilanjutkan Ekstraksi Dengan Pelarut n-
Butanol. Dimana Lapisan air dari hasil ekstraksi eter dimasukkan kembali ke dalam corong pisah, kemudian ditambahkan dengan pelarut n-Butanol sebanyak $50 \mathrm{ml}$, terbentuk dua lapisan untuk lapisan air disimpan dalam wadah, lapisan n-Butanol diuapkan hingga diperoleh ekstrak n-Butanol kering. Selanjutnya ekstrak eter dan ekstrak nButanol dilakukan uji pemisahan senyawa dengan metode bioautografi.t/kering.

2. Penyiapan Bakteri Uji

a. Peremajaan bakteri

Diambil tabung reaksi steril, lalu diisi dengan $5 \mathrm{ml}$ medium Nutrien Agar (NA). Kemudian didiamkan beberapa saat dengan posisi miring. Setelah memadat, diambil biakan murni digoreskan pada permukaan agar miring, diinkubasi pada suhu $37^{\circ} \mathrm{C}$ selama1 x 24 jam.

b. Penyiapan Suspensi Bakteri

Suspensi bakteri dari biakan murni Staphylococcus aureus, ditambahkan larutan natrium klorida fisiologis $(\mathrm{NaCl}) \quad 0,9 \%$ sebanyak $10 \mathrm{ml}$ kedalam biakan tersebut lalu dihomogenkan.

3. Pemisahan dan Pemurnian Komponen Kimia

a. Pembuatan Eluen

Dibuat campuran eluen dengan menggunakan kloroform-metanolair dengan perbandingan (10:6:1), (15:6:1), dan (20:6:1) untuk eluen polar dan heksan : etil asetat dengan perbandingan $(7: 3),(8: 2)$, dan $(9: 1)$ untuk eluen nonpolar, kemudian masing-masing eluen dengan perbandingan yang berbeda-beda dimasukkan ke dalam botol eluen, dikocok-kocok hingga homogen. Larutan eluen dengan perbandingan yang berbeda siap untuk digunakan sebagai uji.

b. Penotolan Sampel Ekstrak

Dipilih salah satu ekstrak daun Sembukan yang telah dilarutkan, ditotolkan pada garis penotolan dengan menggunakan pipa kapiler. Ekstrak eter diidentifikasi secara kromatografi Lapis Tipis dengan menggunakan cairan pengelusi Hexan-etil asetat dengan 
perbandingan (7:3), (8:2), dan (9:1), sedangkan pada ekstrak n-Butanol diidentifikasi menggunakan cairan pengelusi kloroform-metanol-air dengan perbandingan (10:6:1), (15:6:1), dan (20:6:1),pada lempeng Kromatografi lapis tipis (KLT) maka akan terbentuk noda di bawah sinar lampu UV $254 \mathrm{~nm}$ dan hasil yang diperoleh dihitung masingmasing nilai Rf dari tiap-tiap nodanya.

c. Pengujian Aktivitas Antibakteri Secara KLT-Bioautografi

Medium Nutrien Agar (NA) dituang secara aseptik kedalam cawan petri sebanyak $15 \mathrm{ml}$ dan dibiarkan memadat. Ekstrak eter daun Sembukan ditotolkan pada lempeng KLT, lalu dielusi dengan eluen heksan-etil asetat sedangkan ekstrak n-Butanol daun Sembukan ditotolkan pada lempeng dengan eluen kloroform-metanol-air, setelah itu dilihat penampakan noda pada lampu UV $256 \mathrm{~nm}$. Setelah itu masing-masing lempeng diletakan di atas medium agar. Setelah 30 menit lempeng tersebut dipindahkan, kemudian diinkubasi pada suhu $37^{\circ} \mathrm{C}$ selama $1 \times 24$ jam.
Setelah itu diukur zona hambatan pada masing-masing bakteri Staphylococcus aureus yaitu pada diameter daerah bening yang diperoleh.

\section{Pengumpulan dan Analisis Data}

Pengamatan dan pengukuran diameter hambat pada bakteri Staphylococcus aureus dilakukan masa inkubasi 24 jam kemudian zona hambatan yang terbentuk masingmasing diukur dengan menggunakan alat jangka sorong.

\section{Pengamatan dan Pengumpulan data}

Pengamatan data berdasarkan diameter zona hambat yang dilakukan setelah inkubasi $1 \mathrm{x}$ 24 jam padasuhu $37^{\circ} \mathrm{C}$, kemudian di ukur zona hambatan dengan menggunakan jangka sorong.

\section{HASIL DAN PEMBAHASAN}

Hasil penelitian

Dari hasil penelitian dan pengamatan Uji Senyawa Bioaktif Ekstrak Daun Sembukan (Paederia foetida L) terhadap Staphylococcus aureus dengan Metode Bioautografi pada masa inkubasi 24 jam dengan suhu $37^{\circ} \mathrm{c}$, maka diperoleh hasil pengukuran yang dapat dilihat pada tabel dibawah ini

Tabel 1. Hasil nilai Rf dan diameter zona hambat ekstrak eter Daun Sembukan (Paederia foetida L.) dengan eluen Hexan-Etil Asetat (7:3) terhadap Staphylococcus aureus

\begin{tabular}{ccccccc}
\hline & \multicolumn{5}{c}{ Nilai Rf dan Diameter Zona Hambat } \\
\cline { 2 - 7 } Noda & \multicolumn{2}{c}{ I } & \multicolumn{3}{c}{ II } & \multicolumn{2}{c}{ III } \\
\cline { 2 - 7 } & Nilai $R f$ & Diameter & Nilai $R f$ & Diameter & Nilai $R f$ & Diameter \\
\hline 1 & 0,9 & - & 0,91 & - & 0,94 & - \\
2 & 0,85 & $4,75 \mathrm{~mm}$ & 0,82 & $6,5 \mathrm{~mm}$ & 0,84 & $6,25 \mathrm{~mm}$ \\
3 & 0,78 & - & 0,71 & - & 0,78 & - \\
4 & 0,68 & - & 0,6 & - & 0,72 & - \\
5 & 0,61 & - & 0,5 & - & 0,45 & \\
6 & 0,47 & - & 0,38 & - & 0,34 & - \\
\hline
\end{tabular}


Tabel 2. Hasil nilai Rf dan diameter zona hambat ekstrak n-Butanol Daun Sembukan (Paederia foetida L.) dengan eluen Kloroform-Metanol-Air (20:6:1) terhadap Stylococcus aureus.

\begin{tabular}{ccccccc}
\hline & \multicolumn{6}{c}{ Nilai Rf dan Diameter Zona Hambat } \\
\cline { 2 - 7 } Noda & \multicolumn{2}{c}{ I } & \multicolumn{2}{c}{ II } & \multicolumn{2}{c}{ III } \\
\hline & Nilai $R f$ & Diameter & Nilai $R f$ & Diameter & Nilai $R f$ & Diameter \\
\hline 2 & 0,91 & - & 0,94 & - & 0,92 & - \\
3 & 0,71 & - & 0,82 & - & 0,87 & - \\
4 & 0,77 & - & 0,77 & - & 0,78 & - \\
5 & 0,65 & - & 0,72 & - & 0,74 & - \\
6 & 0,55 & - & 0,67 & - & 0,58 & \\
7 & 0,5 & - & 0,6 & - & 0,48 & - \\
8 & 0,35 & $5,25 \mathrm{~mm}$ & 0,47 & $6,75 \mathrm{~mm}$ & 0,37 & $9,5 \mathrm{~mm}$ \\
\hline
\end{tabular}

\section{Pembahasan}

Pada penelitian ini digunakan bahan uji berupa Daun Sembukan (Paederia foetida L.) yang dipetik langsung dari Kabupaten Bulukumba, Sulawesi Selatan. Daun Sembukan (Paederia foetida L.) yang diperoleh, dicuci bersih dengan air mengalir lalu dipotong atau dirajang kecil-kecil lalu diangin-anginkan di tempat yang tidak terkena cahaya matahari langsung.

Tahap selanjutnya sampel Daun Sembukan (Paederia foetida L.) diekstraksi dengan metode meserasi dimana sampel tersebut ditimbang sebanyak 350 gram kemudian dimasukkan ke dalam bejana maserasi dengan ditambahkan pelarut etanol 96\% hingga sampel terendam sempurna dilakukan selama $5 \times 24$ jam dengan pengadukan $1 \times 24$ jam, setelah itu dilakukan penyaringan untuk memisahkan filtrat dan ampasnya, kemudian diuapkan mengunakan rotapavor sehingga menghasilkan ekstrak kental.

Ekstrak yang diperoleh selanjutnya dilakukan pemisahan senyawa kimia dengan menggunakan metode Kromatografi Lapis Tipis (KLT). Senyawa yang telah terpisah akan nampak sebagai noda pada permukaan lempeng KLT dan masing-masing noda memilki nilai $\mathrm{Rf}$ yang berbeda pada pemisahan senyawa dengan metode KLT disebabkan oleh adanya perbedaan daya elusi. Penelitian ini digunakan ekstrak eter dengan eluen Hexan-Etil Asetat (7:3) dan ekstrak n-Butanol dari ekstrak kental daun sembukan (Paederia foetida L.) dengan eluen Kloroform-Metanol-Air (20:6:1) karena pemisahan bercak diberikan lebih baik.

Berdasarkan hasil KLT diporoleh bercak noda yang tidak begitu jelas, tetapi setelah diamati dibawah sinar UV $366 \mathrm{~nm}$ diketahui bahwa pada ekstrak eter Daun Sembukan (Paederia foetida L.) dengan 3 replikasi masing-masing memperlihatkan 6 bercak noda pada replikasi 1 dengan nilai $\mathrm{Rf}_{1}$ 0,9; $\mathrm{Rf}_{2}$ 0,85; $\mathrm{Rf}_{3} 0,78 ; \mathrm{Rf}_{4}$ 0,68; $\mathrm{Rf}_{5}$ 0,61; dan $\mathrm{Rf}_{6} 0,47$, pada replikasi 2 dengan nilai $\mathrm{Rf}_{1}$ 0,91; $\mathrm{Rf}_{2}$ 0,82; $\mathrm{Rf}_{3} 0,71 ; \mathrm{Rf}_{4}$ 0,6; $\mathrm{Rf}_{5}$ 0,5; $\mathrm{Rf}_{6} 0,38$ dan pada replikasi 3 dengan nilai $\mathrm{Rf}_{1}$ 0,94; $\mathrm{Rf}_{2} 0,84 ; \mathrm{Rf}_{3} 0,78 ; \mathrm{Rf}_{4} 0,72 ; \mathrm{Rf}_{5} 0,45$; dan $\mathrm{Rf}_{6}$ 0,34. Hal ini menunjukkan bahwa pada ekstrak eter Daun Sembukan (Paederia foetida L.) terdapat 6 komponen senyawa kimia yang larut dalam pelarut non polar karena ada 6 nilai Rf yang berbeda. Pada ekstrak N-Butanol dengan 3 replikasi masing-masing memperlihatkan 7 bercak noda pada replikasi 1 dengan nilai $\mathrm{Rf}_{1} 0,91$; $\mathrm{Rf}_{2}$ 0,71; Rf $\mathrm{f}_{3} 0,77 ; \mathrm{Rf}_{4} 0,65 ; \mathrm{Rf}_{5} 0,55 ; \mathrm{Rf}_{6} 0,5$; $\mathrm{Rf}_{7}$ 0,35; dan $\mathrm{Rf}_{8} 0,25$,pada replikasi 2 dengan nilai $\mathrm{Rf}_{1} \quad 0,94 ; \mathrm{Rf}_{2} \quad 0,82 ; \mathrm{Rf}_{3} \quad 0,77 ; \mathrm{Rf}_{4} 0_{0,72}$; $\mathrm{Rf}_{5} 0,67 ; \mathrm{Rf}_{6} 0,6 ; \mathrm{Rf}_{7} 0,47 ; \mathrm{Rf}_{8} 0,32$, dan pada replikasi 3 dengan nilai $\mathrm{Rf}_{1} 0,92 ; \mathrm{Rf}_{2} 0,87$; $\mathrm{Rf}_{3}$ 0,78; $\mathrm{Rf}_{4}$ 0,74; $\mathrm{Rf}_{5}$ 0,58; $\mathrm{Rf}_{6}$ 0,48; $\mathrm{Rf}_{7}$ 0,$37 ; \mathrm{Rf}_{8} 0,27$. Hal ini menunjukkan bahwa pada ekstrak n-Butanol Daun Sembukan (Paederia foetida L.) terdapat 8 komponen senyawa kimia yang larut dalam pelarut polar karena ada 8 nilai Rf yang berbeda.

Hasil yang diperoleh dari pemisahan senyawa secara KLT dilanjutkan dengan pengujiaan Bioautografi untuk melihat senyawa bioaktif yang dapat menghambat pertumbuhan Staphylococcus aureus. Daerah 
hambatan pada pengujian secara Bioautografi ekstrak Daun Sembukan (Paederia foetida L.) secara Kromatografi Lapis Tipis (KLT) kemudian dihitung nilai Rfnya. Maka dalam hal ini ditemukan senyawa bioaktif yang dapat menghambat pertumbuhan Staphylococcus aureus. Pada uji aktivitas antibakteri secara bioautografi didapat hasil bahwa kromotogram ekstrak eter dengan 3 replikasi yang menghambat Staphylococcus aureus adalah bercak noda dengan nilai $\mathrm{Rf}$ cawan petri $1=0,85$ zona hambat $=4,75 \mathrm{~mm}$, nilai $R f$ cawan petri $2=0,82$ zona hambat $=$ $6,5 \mathrm{~mm}$, nilai $\mathrm{Rf}$ cawan petri $3=0,84$ zona hambat $=6,25 \mathrm{~mm}$. Pada kromatogram ektsrak n-Butanol dengan 3 replikasi yang menghambat staphylococcus aureus memperlihatkan bercak noda dengan nilai $\mathrm{Rf}$ cawan petri $1=0,35$ zona hambat $=5,25 \mathrm{~mm}$, nilai $R f$ cawan petri $2=0,47$ zona hambat $=$ $6,75 \mathrm{~mm}$, nilai $\mathrm{Rf}$ cawan petri $3=0,37$ zona hambat $9,5 \mathrm{~mm}$. Hal ini menunjukkan bahwa pada ekstrak Daun Sembukan (Paederia foetida L.) yang memiliki zona hambat ditandai dengan adanya warna bening atau transparan yang disebabkan karena proses difusi dari ekstrak Daun Sembukan (Paederia foetida L.) yang berpengaruh terhadap pertumbuhan Staphylococcus aureus.

Zona hambat yang dimiliki daun sembukan Sembukan (Paederia foetida L.) yang berkisar pada 4,75 $\pm 9,5$ dengan tingkat aktivitas antibakteri yang cukup besar dengan ekstrak etanol dari daun Sembukan (Paederia foetida L.) mampu mengatasi bakterii Staphylococcus aureus.

Adapun Beberapa faktor yang dapat mempengaruhi nilai $\mathrm{Rf}$ adalah:

a. Struktur kimia dari senyawa yang dipisahkan

b. Sifat dari penyerap (adsorben) dan derajat aktifitasnya

c. Pelarut sebagai fase gerak dan derajat kemurniannya

d. Kejenuhan dari uap dalam chamber

\section{PENUTUP}

\section{Kesimpulan}

Hasil penelitian Uji Senyawa

Bioaktif Ekstrak Daun Sembukan (Paederia foetida L.) Terhadap Staphylococcus aureus dengan Metode Bioautografi dapat disimpulkan bahwa : Ekstrak eter Daun Sembukan (Paederia foetida L.) dapat memberikan efektifitas terhadap pertumbuhan Staphylococcus aureus pada nilai $R f 0,85$ dengan zona hambat $4,75 \mathrm{~mm}$, nilai $R f 0,82$ zona hambat $6,5 \mathrm{~mm}$, nilai $R f$ 0,84 zona hambat $6,25 \mathrm{~mm}$. Sedangkan Ekstrak n-Butanol Daun Sembukan (Paederia foetida L.) dapat memberikan efektifitas terhadap pertumbuhan Staphylococcus aureus pada nilai $R f 0,35$ dengan zona hambat $5,25 \mathrm{~mm}$, nilai $R f 0,47$ zona hambat $6,75 \mathrm{~mm}$, nilai $R f 0,37$ zona hambat $9,5 \mathrm{~mm}$

\section{DAFTAR PUSTAKA}

Abriyanto, A.E,dkk. 2012. Aktivitas Anti Fungi Ekstrak Etanol Daun Sembukan (Paederia foetida L.) Terhadap Candida albicans. Pharmacy. Vol 9 (3)

Akhyar. 2010. Uji Hambat dan Analisa KLT Bioautografi Ekstrak Akar dan Buah Bakau (Rhizophora stylosa Griff) Terhadap Vibro Harveyi. Jurnal Kefarmasian Universitas Hasanudin Makassar.

Anief, Muhammad. 2011. Ilmu Meracik Obat. Yogyakarta : Gadjah Mada. UI Press

Ansel, H. 2010. Pengantar Bentuk Sediaan Farmasi. Jakarta : UI press

Departemen Kesehatan RI., 2010. Farmakope Indonesia Edisi V. Jakarta : Depkes RI

$\begin{array}{cr}\text { Ervizal, } 2011 . & \text { Dasar-dasar } \\ \text { Mikroorganisme. } & \text { Universitas } \\ \text { Indonesia Press. Jakarta } & \end{array}$

Hariana, A. 2013. Tumbuhan Obat dan Khasiatnya. Jakarta Timur : Penebar Swadaya Cibubur

Hasdianah. 2012. Mikrobiologi. Yogyakarta :Nuha Medika

Khare. 2010. Thin-Layer Chromatography, VCH Publisher, USA.

Misnadiarly,dkk. 2014. Mikrobiologi Untuk Klinik dan Laboratorioum. Jakarta: PT. Rineka Citra

Nurcahyanti, A.D.R dan Wandra, J. 2012. Sembukan Kurang Sedap Namun Berkhasiat Hebat. Bios : Salatiga 
Rohman,A. 2009. Kromatografi Untuk Analisis Obat. Yogyakarta : Graha Ilmu

Salaki, Christina, dkk. 2012. Pemanfaatan Bakteri Bacillus cereus terhadap hama Spodoptera liturs Pada Tanaman Kubis. Vol 18 No. 2. Manado: Unsrat

Sudjadi, 2013. Metode Pemisahan. Penerbit Kansius, Yogyakarta.

Tjitrosoepomo, G. 2013. Taksonomi Tumbuhan. Yogyakarta : Gadjah Mada University Press
Warsa, U.C. 2014. Buku Ajar Mikrobiologi Kedokteran Edisi Revisi. Jakarta : UI Press

Wasito, dkk. 2013. Obat Tradisional Kekayaan Indonesia. Yogyakarta: Graha Ilmu

Widyaningrum, MPH. 2011. Kitab Tanaman Obat Nasional. Jakarta : Media Pressindo

Yenny. Herwanna, Elly. 2013. Resistensi Dari Bakteri Enterik: Aspek Global Terhadap Antimikroba. Jakarta: Fakultas Kedokteran Universitas Trisakti 